\title{
Municipal Leachate Treatment by Fenton Process: Effect of Some Variable and Kinetics
}

\author{
Mohammad Ahmadian, ${ }^{1}$ Sohyla Reshadat, ${ }^{1}$ Nader Yousefi, ${ }^{2}$ \\ Seyed Hamed Mirhossieni, ${ }^{3,4}$ Mohammad Reza Zare, ${ }^{3,4}$ Seyed Ramin Ghasemi, ${ }^{1}$ \\ Nader Rajabi Gilan, ${ }^{1}$ Razieh Khamutian, ${ }^{5}$ and Ali Fatehizadeh ${ }^{3,4}$ \\ ${ }^{1}$ Social Development \& Health Promotion Research Center, Kermanshah University of Medical Sciences, Kermanshah, Iran \\ ${ }^{2}$ Department of Environmental Health Engineering, School of Public Health, Tehran University of Medical Sciences, Tehran, Iran \\ ${ }^{3}$ Environment Research Center, Isfahan University of Medical Sciences (IUMS), Isfahan, Iran \\ ${ }^{4}$ Department of Environmental Health Engineering, School of Health, IUMS, Isfahan, Iran \\ ${ }^{5}$ Faculty of Public Health, Kermanshah University of Medical Sciences, Kermanshah, Iran
}

Correspondence should be addressed to Ali Fatehizadeh; fatehizadeh@gmail.com

Received 1 January 2013; Revised 18 April 2013; Accepted 19 April 2013

Academic Editor: Mohammad Mehdi Amin

Copyright (C) 2013 Mohammad Ahmadian et al. This is an open access article distributed under the Creative Commons Attribution License, which permits unrestricted use, distribution, and reproduction in any medium, provided the original work is properly cited.

\begin{abstract}
Due to complex composition of leachate, the comprehensive leachate treatment methods have been not demonstrated. Moreover, the improper management of leachate can lead to many environmental problems. The aim of this study was application of Fenton process for decreasing the major pollutants of landfill leachate on Kermanshah city. The leachate was collected from Kermanshah landfill site and treated by Fenton process. The effect of various parameters including solution $\mathrm{pH}, \mathrm{Fe}^{2+}$ and $\mathrm{H}_{2} \mathrm{O}_{2}$ dosage, $\mathrm{Fe}^{2+} / \mathrm{H}_{2} \mathrm{O}_{2}$ molar ratio, and reaction time was investigated. The result showed that with increasing $\mathrm{Fe}^{2+}$ and $\mathrm{H}_{2} \mathrm{O}_{2}$ dosage, $\mathrm{Fe}^{2+} / \mathrm{H}_{2} \mathrm{O}_{2}$ molar ratio, and reaction time, the COD, TOC, TSS, and color removal increased. The maximum COD, TOC, TSS, and color removal were obtained at low $\mathrm{pH}(\mathrm{pH}: 3)$. The kinetic data were analyzed in term of zero-order, first-order, and second-order expressions. First-order kinetic model described the removal of COD, TOC, TSS, and color from leachate better than two other kinetic models. In spite of extremely difficulty of leachate treatment, the previous results seem rather encouraging on the application of Fenton's oxidation.
\end{abstract}

\section{Introduction}

In the past decades, industrial growth and technology development lead to the increasing solid waste production [1]. According to the World Health Organization studies, in the many countries such as France, Canada, America, Norway, England, Spain, and Italy, sanitary landfilling had been recognized as the common, economic and acceptable method for solid waste disposal [2-4]. Landfill leachate is a complex waste matter, which usually causes adverse effects in the environment $[5,6]$. The leachate characteristics are depended on the type of solid waste, soil properties, rainfall patterns, and age of landfill site. The concentration of nonbiodegradable and resistant materials with high molecular weight such as humic and fulvic acid arises with increase of the landfill site age [7].

Due to variable characteristic of landfill leachate, the coherent method for leachate treatment was not developed [8]. The concerning of solid waste leachate may be related to presence of heavy metals and nonbiodegradable organic materials in solid waste leachate and its adverse effects on human and the environment [3]. Application of biological treatment processes (as dominant treatment) cannot remove nonbiodegradable organic materials and additional treatments are required for leachate treatment [9]. Biological treatment processes are suitable for fresh leachate with high ratio of $\mathrm{BOD}_{5} / \mathrm{COD}$ but cannot be applied in the treatment 
of aged leachate in which biological treatment occurred, and ratio of $\mathrm{BOD}_{5} / \mathrm{COD}$ is low [10].

Chemical treatment methods based on production of hydroxyl radical $\left(\mathrm{OH}^{\bullet}\right)$ are known as advanced oxidation processes $\left(\mathrm{AOP}_{\mathrm{s}}\right)[11,12]$. Oxidation of organic compounds by Fenton solution called the Fenton reaction which is one of the advanced oxidation processes [13]. Fenton reaction is able to destroyed large number of organic compounds without producing toxic byproducts. Another main advantage of Fenton process is that the oxidation and flocculation occur simultaneously that result in removing more organic matters [14].

Fenton process is done according to the following mechanism [3]:
(1) $\mathrm{Fe}^{2+}+\mathrm{H}_{2} \mathrm{O}_{2} \rightarrow \mathrm{Fe}^{3+}+{ }^{\circ} \mathrm{OH}+\mathrm{OH}^{-}$,
(2) $\mathrm{Fe}^{2+}+\mathrm{H}_{2} \mathrm{O}_{2} \rightarrow \mathrm{Fe}^{2+}+\mathrm{HO}_{2}^{\cdot}+\mathrm{H}^{+}$,
(3) ${ }^{\bullet} \mathrm{OH}+\mathrm{H}_{2} \mathrm{O}_{2} \rightarrow \mathrm{HO}_{2}^{\bullet}+\mathrm{H}_{2} \mathrm{O}$,
(4) ${ }^{\bullet} \mathrm{OH}+\mathrm{Fe}^{2+} \rightarrow \mathrm{OH}^{-}+\mathrm{Fe}^{3+}$,
(5) $\mathrm{Fe}^{3+}+\mathrm{HO}_{2}^{\cdot} \rightarrow \mathrm{Fe}^{2+}+\mathrm{O}_{2} \mathrm{H}^{+}$,
(6) $\mathrm{Fe}^{2+}+\mathrm{HO}_{2}^{\circ}+\mathrm{H}^{+} \rightarrow \mathrm{Fe}^{3+}+\mathrm{H}_{2} \mathrm{O}_{2}$,
(7) $2 \mathrm{OH}_{2}^{\bullet} \rightarrow \mathrm{H}_{2} \mathrm{O}_{2}+\mathrm{O}_{2}$.

Oxidation potential of hydroxyl radical $\left(\mathrm{OH}^{\bullet}\right)$ is greater than ozone, one of the strongest oxidizing materials [15]. Hydrogen peroxide alone is not a strong factor in oxygen transfer, and oxidation of organic materials is better performed in the presence of $\mathrm{Fe}^{2+}$ ions [16]. The most important role of Fenton process is removing refractory and toxic organic compounds and increasing the degradability of resistant organic compounds. Fenton processes have been successfully used for treatment of the slaughterhouse, food, olive oil wastewater, and 2,4,6-trichlorophenol from industrial wastewater and landfill leachate $[15,17-22]$. This method compared to other advanced oxidation processes is relatively less expensive and requires less time [23].

The aim of this study was to investigate the effect of Fenton process for solid waste leachate treatment from Kermanshah landfill (Iran).

\section{Experimental}

2.1. Leachate Characteristics. The Leachate sample was collected from the municipal solid waste landfill in Kermanshah city (Iran). The main characteristics of leachate were summarized in Table 1.

2.2. Chemicals. All chemicals were of analytical grade (Merck, Germany), and doubly distilled water was used throughout this study. The hydrogen peroxide $(35 \% \mathrm{w} / \mathrm{w})$ and ferrous sulphate $\left(\mathrm{FeSO}_{4} \cdot 7 \mathrm{H}_{2} \mathrm{O}\right)$ were used for all experiment. The $\mathrm{FeSO}_{4}$ solution was prepared daily. $\mathrm{H}_{2} \mathrm{SO}_{4}$ and $\mathrm{NaOH}$ $(1 \mathrm{~N})$ were used for $\mathrm{pH}$ adjustment.

2.3. Experimental Procedure. In this study, the effect of Fenton process of leachate treatment was conducted in
TABLE 1: Main characteristics of Kermanshah leachate.

\begin{tabular}{lcc}
\hline Parameter & Value & Unit \\
\hline Color & Dark brown & - \\
BOD $_{5}$ & 800 & $\mathrm{mg} / \mathrm{L}$ \\
COD & $3895 \pm 180$ & $\mathrm{mg} / \mathrm{L}$ \\
TOC & $1438 \pm 95$ & $\mathrm{mg} / \mathrm{L}$ \\
TSS & $1460 \pm 80$ & $\mathrm{mg} / \mathrm{L}$ \\
Alkalinity & $2154 \pm 130$ & $\mathrm{mg} / \mathrm{L}$ \\
Color & $3045 \pm 45$ & $\mathrm{Pt}-\mathrm{Co}$ \\
pH & $7.8 \pm 0.1$ & - \\
\hline
\end{tabular}

environment temperature in glass reactor using jar apparatus as a batch reactor. At first, rapid mix $(120 \mathrm{rpm})$ was applied for $30 \mathrm{~s}$, and then mixers were adjusted for $80 \mathrm{rpm}$ for long time. The effect of various parameters including solution $\mathrm{pH}$, $\mathrm{Fe}^{2+}$ and $\mathrm{H}_{2} \mathrm{O}_{2}$ concentrations, $\mathrm{Fe}^{2+} / \mathrm{H}_{2} \mathrm{O}_{2}$ molar ratio, and reaction time was investigated. All experiments were carried out with $1 \mathrm{~L}$ beakers, and the beakers were charged with $500 \mathrm{~mL}$ leachate [24].

2.4. Analytical Methods. The amounts of $\mathrm{pH}, \mathrm{COD}, \mathrm{TOC}$, TSS, color, and alkalinity were analyzed in the laboratory by following the standard methods [25]. The $\mathrm{pH}$, TOC, color, and alkalinity measurements were performed by using the WTW Multiparameter 340i, Shimadzu model TOC$\mathrm{CSH}$, spectrophotometer, and titration method, respectively. Closed reflux colorimetric method was used for COD analysis. For COD measurement of the supernatant, supernatant was put in the water bath at $50^{\circ} \mathrm{C}$ for $30 \mathrm{~min}$ for removal of remaining $\mathrm{H}_{2} \mathrm{O}_{2}$ in Fenton process experiments [3]. The removal efficiency was calculated by the following equations:

$$
R=\left[\frac{C_{0}-C_{e}}{C_{0}}\right] \times 100
$$

\section{Results}

3.1. Effect of Solution $p H$. The Fenton process efficiency for COD, TOC, TSS, and color removal as a function of solution $\mathrm{pH}$ was investigated (Figure 1). According to Figure 1, at low $\mathrm{pH}$, the COD, TOC, TSS, and color removal efficiency are low, and with increasing $\mathrm{pH}$ up to 3, removal efficiency increased. After this point, COD, TOC, TSS, and color removal were decreased.

The solution $\mathrm{pH}$ plays an important role in Fenton process. Figure 1 is evident that with increasing the initial $\mathrm{pH}$ from 1 to 3 , the removal efficiency quickly increases and at $\mathrm{pH}>3$ decreases. The results from this experiment are in line with those studies reported by the researchers [6, 23, 26, 27]. They found that $\mathrm{pH}$ near 3 is usually optimum for Fenton oxidation. The low efficiency of Fenton process at $\mathrm{pH}<3$ is due to the formation of $\left[\mathrm{Fe}(\mathrm{II})\left(\mathrm{H}_{2} \mathrm{O}\right)_{6}\right]^{2+}$ complex, which reacts more slowly with $\mathrm{H}_{2} \mathrm{O}_{2}$ than $\left[\mathrm{Fe}(\mathrm{II})(\mathrm{OH})\left(\mathrm{H}_{2} \mathrm{O}\right)_{5}\right]^{+}$and therefore produces lower $\mathrm{OH}$ radical [28]. Also, if the solution $\mathrm{pH}$ is too high, the iron precipitates as $\mathrm{Fe}(\mathrm{OH})_{3}$ and $\mathrm{H}_{2} \mathrm{O}_{2}$ 
TABLE 2: Equations and linear forms and results of kinetics model.

\begin{tabular}{|c|c|c|c|c|c|c|c|}
\hline Kinetic model & Equation & Linear form & Parameter & COD & TOC & TSS & Color \\
\hline \multirow{2}{*}{ Zero-order } & \multirow{2}{*}{$r_{c}=\frac{d C}{d t}=k_{0}$} & \multirow{2}{*}{$C-C_{0}=-k_{0} t$} & $K_{0}$ & 27.93 & 4.48 & 9.04 & 18.58 \\
\hline & & & $R^{2}$ & 0.93 & 0.88 & 0.94 & 0.76 \\
\hline \multirow{2}{*}{ First-order } & \multirow{2}{*}{$r_{c}=\frac{d C}{d t}=k_{1} C$} & \multirow{2}{*}{$\ln \frac{C}{C_{0}}=-k_{1} t$} & $K_{1}$ & 0.012 & 0.004 & 0.009 & 0.013 \\
\hline & & & $R^{2}$ & 0.98 & 0.92 & 0.99 & 0.91 \\
\hline \multirow{2}{*}{ Second-order } & \multirow{2}{*}{$r_{c}=\frac{d C}{d t}=k_{2} C^{2}$} & \multirow{2}{*}{$\frac{1}{C}-\frac{1}{C_{0}}=k_{2} t$} & $K_{2}$ & $6 \times 10^{-6}$ & $4 \times 10^{-6}$ & $1 \times 10^{-5}$ & $1 \times 10^{-5}$ \\
\hline & & & $R^{2}$ & 0.97 & 0.91 & 0.95 & 0.94 \\
\hline
\end{tabular}

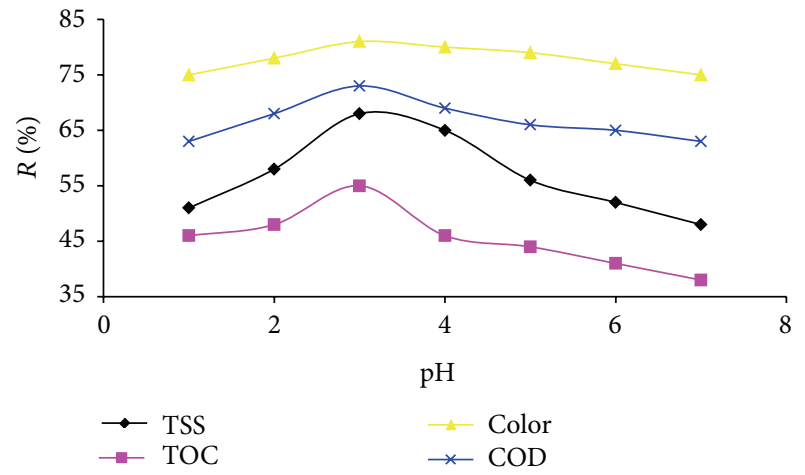

FIGURE 1: Influence of solution $\mathrm{pH}$ on COD, TOC, TSS, and color removal $\left(\mathrm{H}_{2} \mathrm{O}_{2} / \mathrm{Fe}^{2+}\right.$ : fixed and 90 min reaction time).

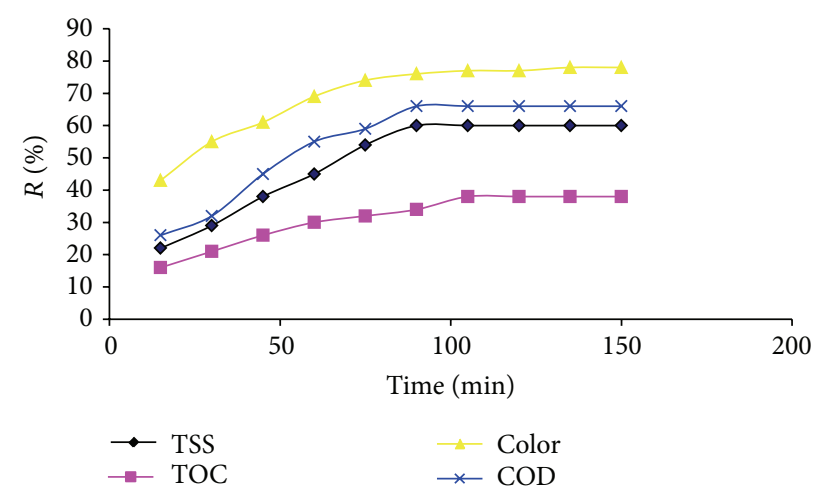

Figure 2: Effect of reaction time in Fenton process on COD, TOC, TSS, and color removal $\left(\mathrm{H}_{2} \mathrm{O}_{2} / \mathrm{Fe}^{2+}\right.$ : fixed and $\left.\mathrm{pH}: 3\right)$.

decompose to oxygen and that will reduce its concentration in the solution $[29,30]$.

3.2. Effect of Reaction Time. The effect of reaction time on COD, TOC, TSS, and color removal during Fenton process is presented in Figure 2. The result showed that with rising reaction time, the COD, TOC, TSS, and color removal increased. The equilibrium time for COD, TOC, TSS, and color removal was obtained, $105 \mathrm{~min}$. After the equilibrium time, the COD, TOC, TSS, and color removal did not change significantly.

Reaction time is an important factor in Fenton process. Different reaction time was reported in various studies. The reaction time for Fenton process in various studies has been

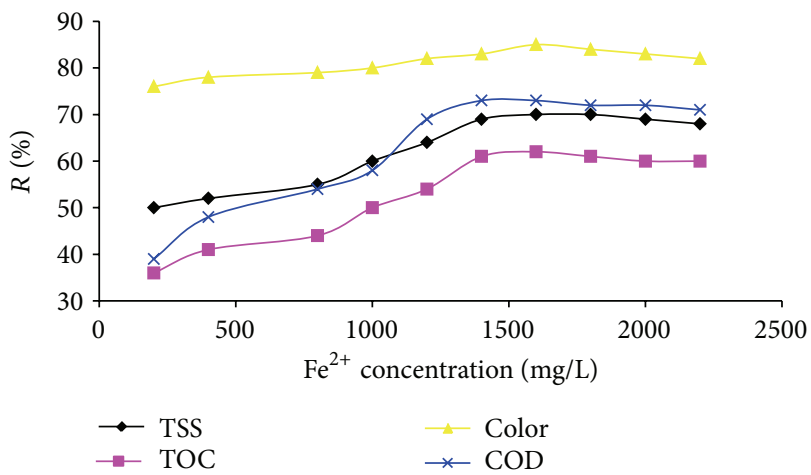

FIGURE 3: Effect of $\mathrm{Fe}^{2+}$ concentration on COD, TOC, TSS, and color removal $\left(\mathrm{H}_{2} \mathrm{O}_{2}: 2500 \mathrm{mg} / \mathrm{L}, \mathrm{pH}: 3\right.$, and $105 \mathrm{~min}$ reaction time).

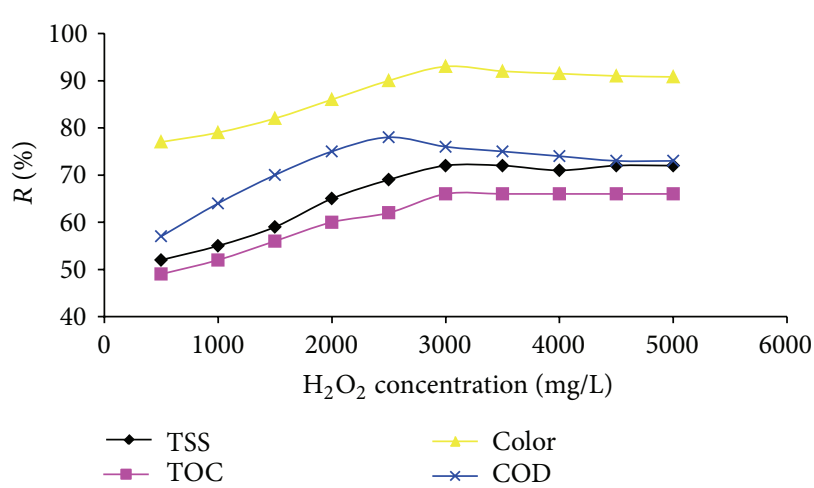

FIgUre 4: Influence of $\mathrm{H}_{2} \mathrm{O}_{2}$ dose on COD, TOC, TSS, and color removal $\left(\mathrm{Fe}^{2+}: 1800 \mathrm{mg} / \mathrm{L}, \mathrm{pH}: 3\right.$, and $105 \mathrm{~min}$ reaction time).

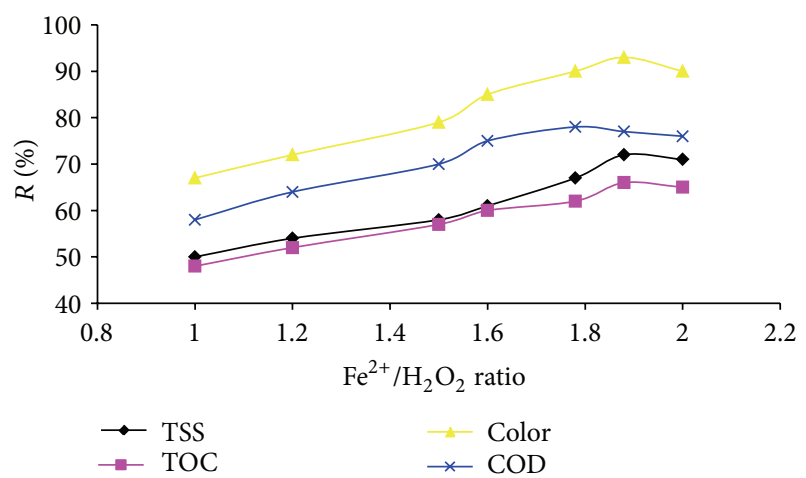

FIGURE 5: Effect of $\mathrm{Fe}^{2+} / \mathrm{H}_{2} \mathrm{O}_{2}$ molar ratio on COD, TOC, TSS, and color removal ( $\mathrm{pH}$ : 3 and $105 \mathrm{~min}$ reaction time). 


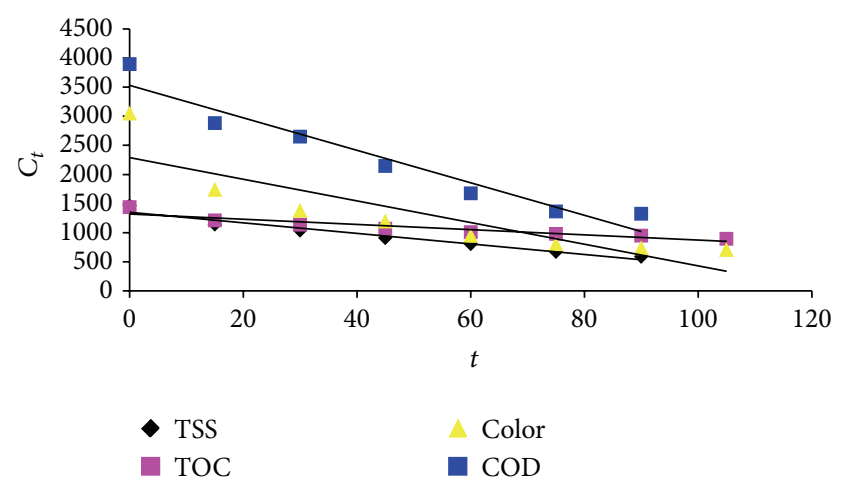

(a)

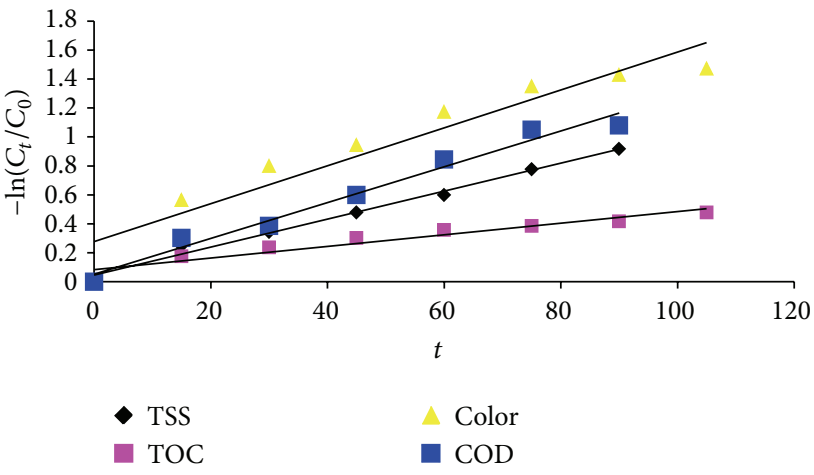

(b)

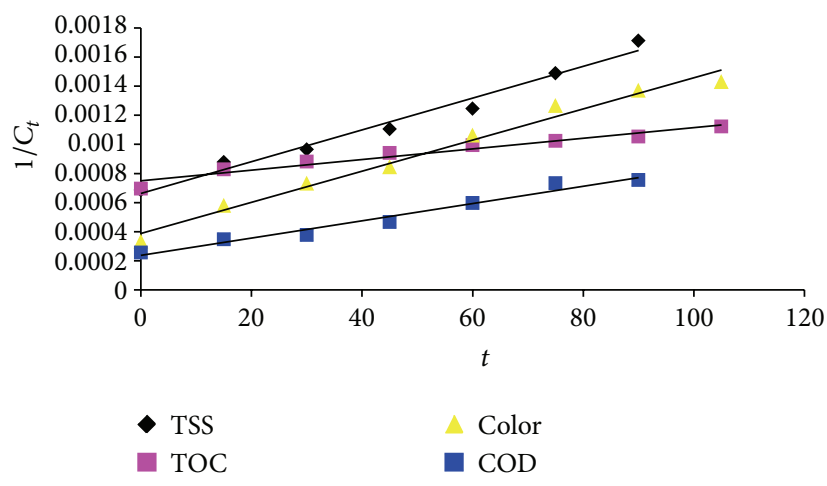

(c)

FIGURE 6: The results of kinetic study: zero-order (a), first-order (b), and second-order (c).

fluctuated between $30 \mathrm{~min}$ and $3 \mathrm{~h}[6,23,27]$. In some studies, based on electro-Fenton process, optimum reaction time has been reported less than $30 \mathrm{~min}$ [1].

3.3. Effect of $\mathrm{Fe}^{2+}$ Concentration. Figure 3 shows the effect of $\mathrm{Fe}^{2+}$ concentration on the COD, TOC, TSS, and color removal during Fenton process. It can be seen that the Fenton efficiency of COD, TOC, TSS, and color removal increases with augmenting $\mathrm{Fe}^{2+}$ concentration. The optimum $\mathrm{Fe}^{2+}$ concentration for maximum COD, TOC, TSS, and color removal was $1.6 \mathrm{~g} / \mathrm{L}$. Further increase of $\mathrm{Fe}^{2+}$ concentration results in decrease in COD, TOC, TSS, and color removal efficiency.

Based on operational costs and organic material removal efficiency, dosage of Fenton reagents will be determined. Generally, removal of organic matters improves with increasing concentration of iron salt. However, the removal increment may be marginal when the concentration of iron salt is high. Many studies have revealed that the use of a much higher concentration of $\mathrm{Fe}^{2+}$ could lead to the self-inhibition of $\mathrm{OH}$ radical by $\mathrm{Fe}^{2+}$ ions and decreasing the degradation rate of pollutants: ${ }^{\bullet} \mathrm{OH}+\mathrm{Fe}^{2+} \rightarrow \mathrm{Fe}^{3+}+\mathrm{OH}^{-}[30]$.

3.4. Effect of $\mathrm{H}_{2} \mathrm{O}_{2}$ Dose. The influence of $\mathrm{H}_{2} \mathrm{O}_{2}$ dose on COD, TOC, TSS, and color removal is shown in Figure 4. The results showed that removal efficiency of COD, TOC, TSS, and color gradually increases as the $\mathrm{H}_{2} \mathrm{O}_{2}$ concentration is fluctuated from $500 \mathrm{mg} / \mathrm{L}$ to $3000 \mathrm{mg} / \mathrm{L}$ and then slowly decreased. It was observed that maximum COD, TOC, TSS, and color removal were obtained at $\mathrm{H}_{2} \mathrm{O}_{2}$ concentration of $3000 \mathrm{mg} / \mathrm{L}$.

Landfill leachate is composed of a complex mixture of organic matter. During the oxidation process, more decomposition of organic matter causes more pollutant removal. This continues until formation of the end byproducts of oxidation reactions that mainly are short chain organic acids and are difficult to be further oxidized [13]. The presence of $\mathrm{H}_{2} \mathrm{O}_{2}$ in a high quantity can act as a scavenger for the $\mathrm{OH}$ radicals, thus reducing the kinetic rate of Fenton process [31]. In addition, due to decomposition of $\mathrm{H}_{2} \mathrm{O}_{2}$ and producing hydrogen gas, application of $\mathrm{H}_{2} \mathrm{O}_{2}$ more than the optimum value are caused flotation of generated iron sludge. Also, additional $\mathrm{H}_{2} \mathrm{O}_{2}$ causes problems in downstream processes and will prevent wastewater biological treatment $[3,32]$.

3.5. Effect of $\mathrm{Fe}^{2+} / \mathrm{H}_{2} \mathrm{O}_{2}$ Molar Ratio. The effect of $\mathrm{Fe}^{2+} / \mathrm{H}_{2} \mathrm{O}_{2}$ molar ratio on the COD, TOC, TSS, and color removal with different $\mathrm{Fe}^{2+} / \mathrm{H}_{2} \mathrm{O}_{2}$ molar ratios within a range of 1 to 2 is presented in Figure 5. It can be seen that COD, TOC, TSS, and color removal increase with the rise in $\mathrm{Fe}^{2+} / \mathrm{H}_{2} \mathrm{O}_{2}$ molar ratio up to 1.88 and after this ratio decrease.

In Fenton process, iron and hydrogen peroxide are two major chemicals that determining operation costs as well as efficiency. Determination of the favorable amount of Fenton's reagent is highly important. The results showed that 
removal efficiencies increased with the increase of $\mathrm{H}_{2} \mathrm{O}_{2} / \mathrm{Fe}^{2+}$ molar ratio, and further increase in $\mathrm{H}_{2} \mathrm{O}_{2} / \mathrm{Fe}^{2+}$ molar ratio produced less efficient improvement in removals. This fact is due to Fenton's reaction mechanisms proposed by other researchers [27]. If $\mathrm{H}_{2} \mathrm{O}_{2} / \mathrm{Fe}^{2+}$ molar ratio is low, the reaction rate follows second pseudoorder up to the stoichiometry ratio of $2 \mathrm{Fe}(\mathrm{II}) \cong \mathrm{H}_{2} \mathrm{O}_{2}$. But, when the $\mathrm{H}_{2} \mathrm{O}_{2} / \mathrm{Fe}^{2+}$ molar ratio increases, the reaction kinetics approache toward zero order. However, at high $\mathrm{H}_{2} \mathrm{O}_{2} / \mathrm{Fe}^{2+}$ molar ratios, the mechanism changed, and the reaction became independent of hydrogen peroxide [29].

3.6. Kinetic Study of Leachate Treatment by Fenton Process. Reaction rates in the reactor must be specially determined to complete description and design of a reactor system and its direct effect on reactor size. Therefore, the study of reaction kinetics to prediction of pollutant removal rates is very important in designing and modeling of treatment process [33].

Determination of the kinetics of the Fenton on COD, TSS, TOC, and color removal reaction is needed to estimate the time required for COD, TSS, TOC, and color removal. A kinetic analysis was conducted by fitting the time-course performance data with zero-, first-, and pseudo-second-order kinetic equations as shown in Table 2.

Where $r_{c}$ is the rate of conversion, $k_{0}, k_{1}$, and $k_{2}$ are reaction rate coefficients, $t$ is time, and $C_{0}$ and $C$ are the initial and final concentration of the constituent in the liquid, respectively. The data were appropriately explained with first-order kinetic model (higher $R^{2}$ ), that presented that the model can successfully simulate COD, TSS, TOC, and color removal in the Fenton process. This results show high relationship between COD, TSS, TOC, and color removal efficiency and its initial concentration. In studies carried out by Guedes et al. and Yasar et al, in removal of synthetic dye by Fenton process, reaction rate is described with first-order kinetic model $[17,34]$. The effects of COD, TSS, TOC, and color removal in the Fenton process are shown in Figure 6.

According to Figure 6, the linear relation for each pollutant removal confirms the fact that the kinetics of COD, TSS, TOC and color removal adherents of the exponential law with time.

Results showed that application of Fenton process is inadequate for landfill leachate treatment of Kermanshah city, but leachate characteristics could be greatly improved by Fenton process. The most important role of Fenton process is removing organic and toxic organic compounds and increasing the degradability of resistant organic compounds. Thus this process can be used as pretreatment for biological treatment. The main disadvantage of the Fenton process is that it requires disposal of excess sludge production.

\section{Acknowledgments}

Financial support for this study was provided by Kermanshah University of Medical Science under research project. Also appreciation is due to Social Development \& Health Promotion Research Center to support approval of this research.

\section{References}

[1] S. H. Lin and C. C. Chang, "Treatment of landfill leachate by combined electro-Fenton oxidation and sequencing batch reactor method," Water Research, vol. 34, no. 17, pp. 4243-4249, 2000.

[2] J. Bohdziewicz and A. Kwarciak, "The application of hybrid system UASB reactor-RO in landfill leachate treatment," Desalination, vol. 222, no. 1-3, pp. 128-134, 2008.

[3] Y. Deng and J. D. Englehardt, "Treatment of landfill leachate by the Fenton process," Water Research, vol. 40, no. 20, pp. 36833694, 2006.

[4] Z. Salem, K. Hamouri, R. Djemaa, and K. Allia, "Evaluation of landfill leachate pollution and treatment," Desalination, vol. 220, no. 1-3, pp. 108-114, 2008.

[5] H. Timur and I. Özturk, "Anaerobic sequencing batch reactor treatment of landfill leachate," Water Research, vol. 33, no. 15, pp. 3225-3230, 1999.

[6] Y. W. Kang and K.-Y. Hwang, "Effects of reaction conditions on the oxidation efficiency in the Fenton process," Water Research, vol. 34, no. 10, pp. 2786-2790, 2000.

[7] C. Di Iaconi, R. Ramadori, and A. Lopez, "Combined biological and chemical degradation for treating a mature municipal landfill leachate," Biochemical Engineering Journal, vol. 31, no. 2, pp. 118-124, 2006.

[8] D. Kulikowska and E. Klimiuk, "The effect of landfill age on municipal leachate composition," Bioresource Technology, vol. 99, no. 13, pp. 5981-5985, 2008.

[9] I. Ozturk, M. Altinbas, I. Koyuncu, O. Arikan, and C. GomecYangin, "Advanced physico-chemical treatment experiences on young municipal landfill leachates," Waste Management, vol. 23, no. 5, pp. 441-446, 2003.

[10] Y. Deng and J. D. Englehardt, "Electrochemical oxidation for landfill leachate treatment," Waste Management, vol. 27, no. 3, pp. 380-388, 2007.

[11] M. Pérez, F. Torrades, X. Domènech, and J. Peral, "Fenton and photo-Fenton oxidation of textile effluents," Water Research, vol. 36, no. 11, pp. 2703-2710, 2002.

[12] M. A. Zazouli, Z. Yousefi, A. Eslami, and M. B. Ardebilian, "Municipal solid waste landfill leachate treatment by fenton, photo-fenton and fenton-like processes: effect of some variables," Iranian Journal of Environmental Health Science and Engineering, vol. 9, no. 1, 2012.

[13] G. López-Cueto, M. Ostra, C. Ubide, and J. Zuriarrain, "Fenton's reagent for kinetic determinations," Analytica Chimica Acta, vol. 515, no. 1, pp. 109-116, 2004.

[14] K. Barbusiński and K. Filipek, "Aerobic sludge digestion in the presence of chemical oxidizing agents part II. Fenton's reagent," Polish Journal of Environmental Studies, vol. 9, no. 3, pp. 145-149, 2000.

[15] T. Dantas, H. Jose, and F. Moreira, "Fenton and photo-Fenton oxidation of tannery wastewater," Acta Scientiarum Tehnology, vol. 25, pp. 91-95, 2003.

[16] M. Panizza and G. Cerisola, "Removal of organic pollutants from industrial wastewater by electrogenerated Fenton's reagent," Water Research, vol. 35, no. 16, pp. 3987-3992, 2001.

[17] A. M. F. M. Guedes, L. M. P. Madeira, R. A. R. Boaventura, and C. A. V. Costa, "Fenton oxidation of cork cooking wastewater: overall kinetic analysis," Water Research, vol. 37, no. 13, pp. 30613069, 2003. 
[18] M. Aliabadi, S. Fazel, and F. VahabZadeh, "Application of acid cracking and Fenton process in treating olive Mill Wastewater," Iranian Journal of Water and Wastewater, vol. 57, pp. 30-36, 2006.

[19] M. Farokhi and A. Mesdaghinia, "Study the kinetics of activated sludge in integrated system (Fenton oxidation/activated sludge) for removal of 2, 4, 6 trichlorophenol," Journal of Gilan University Medical Sciences, vol. 53, pp. 24-30, 2005 (Persian).

[20] D. Hermosilla, M. Cortijo, and C. P. Huang, "Optimizing the treatment of landfill leachate by conventional Fenton and photo-Fenton processes," Science of the Total Environment, vol. 407, no. 11, pp. 3473-3481, 2009.

[21] H. Zhang, D. Zhang, and J. Zhou, "Removal of COD from landfill leachate by electro-Fenton method," Journal of Hazardous Materials, vol. 135, no. 1-3, pp. 106-111, 2006.

[22] M. Ahmadian, N. Yousefi, S. W. V. Ginkel, M. R. Zare, S. Rahimi, and A. Fatehizadeh, "Kinetic study of slaughterhouse wastewater treatment by electrocoagulation using Fe electrodes," Water Science and Technology, vol. 66, pp. 754-760, 2012.

[23] L. Tengrui, A. Al-Harbawi, Z. Jun, and L. M. Bo, "The effect and its influence factors of the Fenton process on the old landfill leachate," Journal of Applied Sciences, vol. 7, no. 5, pp. 724-727, 2007.

[24] M. Malakootian, N. Yousefi, A. Fatehizadeh et al., "Nickel (II) removal from industrial plating effluent by fenton process," Environmental Engineering and Management Journal. In press.

[25] American Public Health Association and Water Environment Federation, Standard Methods for the Examination of Water and Wastewater, American Public Health Association, Washington, DC, USA, 21st edition, 2005.

[26] D. Petruzzelli, G. Boghetich, G. Petrella et al., "Pre-treatment of industrial landfill leachate by Fenton's oxidation," Global NEST Journal, vol. 9, pp. 51-56, 2007.

[27] H. Zhang, J. C. Heung, and C.-P. Huang, "Optimization of Fenton process for the treatment of landfill leachate," Journal of Hazardous Materials, vol. 125, no. 1-3, pp. 166-174, 2005.

[28] H. Gallard, J. De Laat, and B. Legube, "Spectrophotometric study of the formation of iron(III)-hydroperoxy complexes in homogeneous aqueous solutions," Water Research, vol. 33, no. 13, pp. 2929-2936, 1999.

[29] L. Lunar, D. Sicilia, S. Rubio, D. Pérez-Bendito, and U. Nickel, "Degradation of photographic developers by Fenton's reagent: condition optimization and kinetics for metol oxidation," Water Research, vol. 34, no. 6, pp. 1791-1802, 2000.

[30] F. Fu, Q. Wang, and B. Tang, "Fenton and Fenton-like reaction followed by hydroxide precipitation in the removal of $\mathrm{Ni}(\mathrm{II})$ from NiEDTA wastewater: a comparative study," Chemical Engineering Journal, vol. 155, no. 3, pp. 769-774, 2009.

[31] T. Yilmaz, A. Aygün, A. Berktay, and B. Nas, "Removal of COD and colour from young municipal landfill leachate by Fenton process," Environmental Technology, vol. 31, no. 14, pp. 1635$1640,2010$.

[32] Y. Deng, "Physical and oxidative removal of organics during Fenton treatment of mature municipal landfill leachate," Journal of Hazardous Materials, vol. 146, no. 1-2, pp. 334-340, 2007.

[33] G. Tchobanoglous, F. Burton, and H. Stensel, Wastewater Engineering: Treatment, Disposal and Reuse, McGraw-Hill, New York, NY, USA, 2003.

[34] A. Yasar, N. Ahmad, A. A. A. Khan, H. Khan, and M. Khalid, "Kinetics of UV, Fenton and Photo Fenton processes for decolorization of various red CL-5B dye concentrations," Journal of Applied Sciences, vol. 7, no. 16, pp. 2339-2344, 2007. 


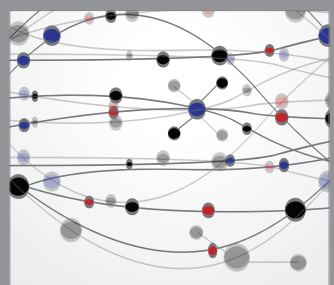

The Scientific World Journal
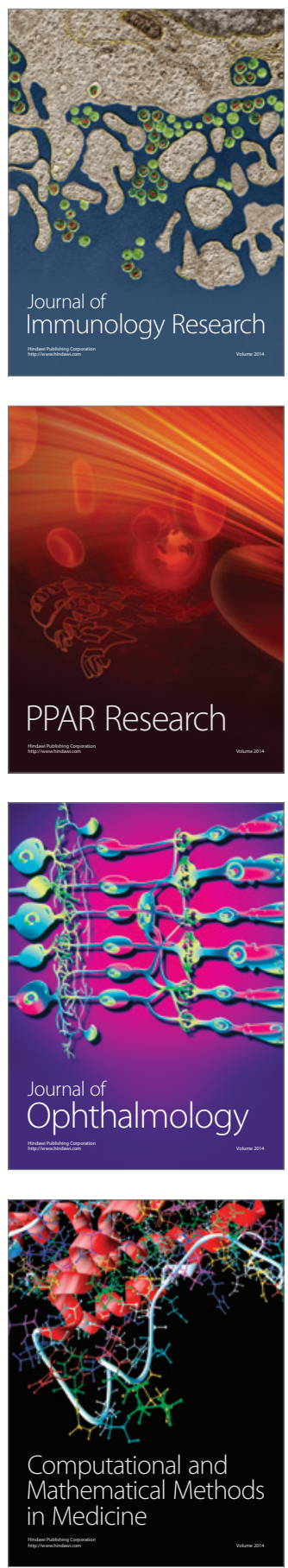

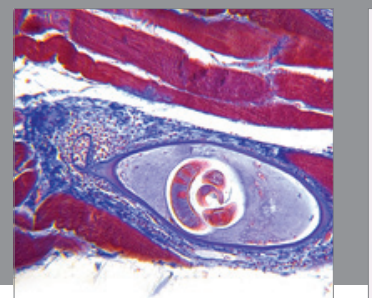

Gastroenterology

Research and Practice
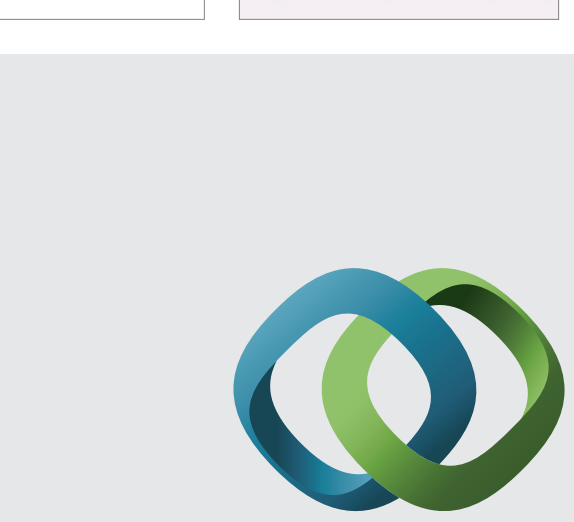

\section{Hindawi}

Submit your manuscripts at

http://www.hindawi.com
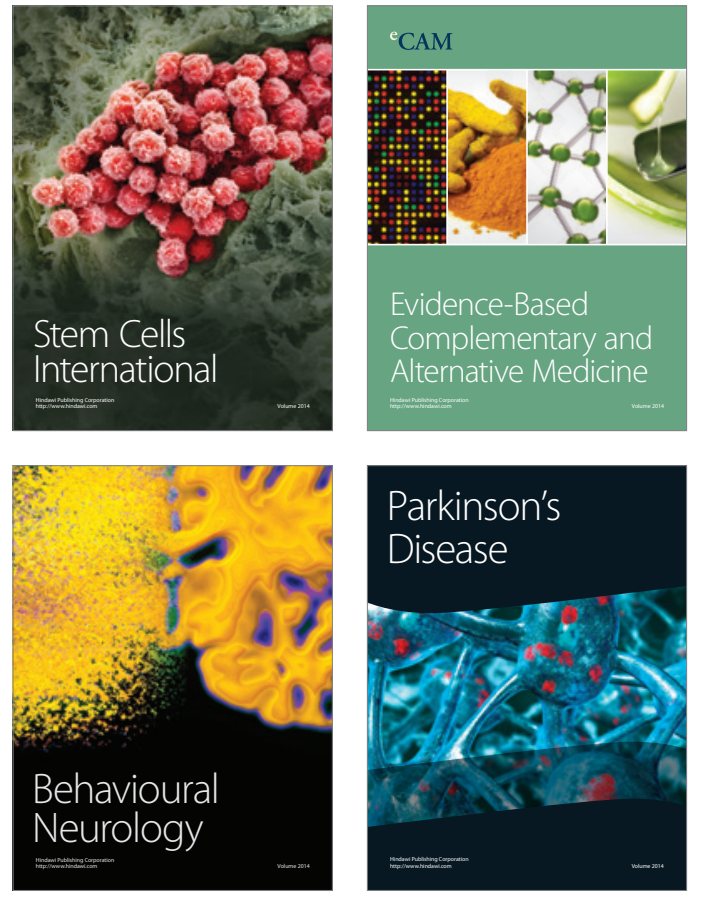
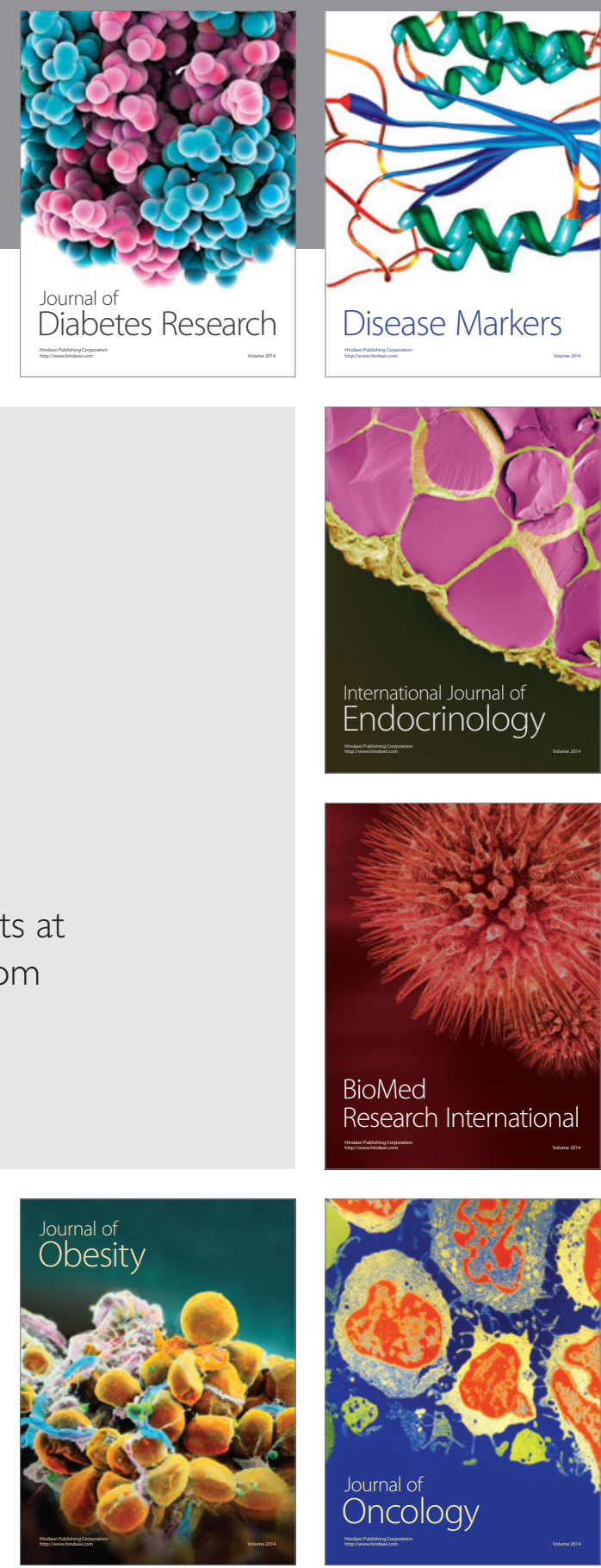

Disease Markers
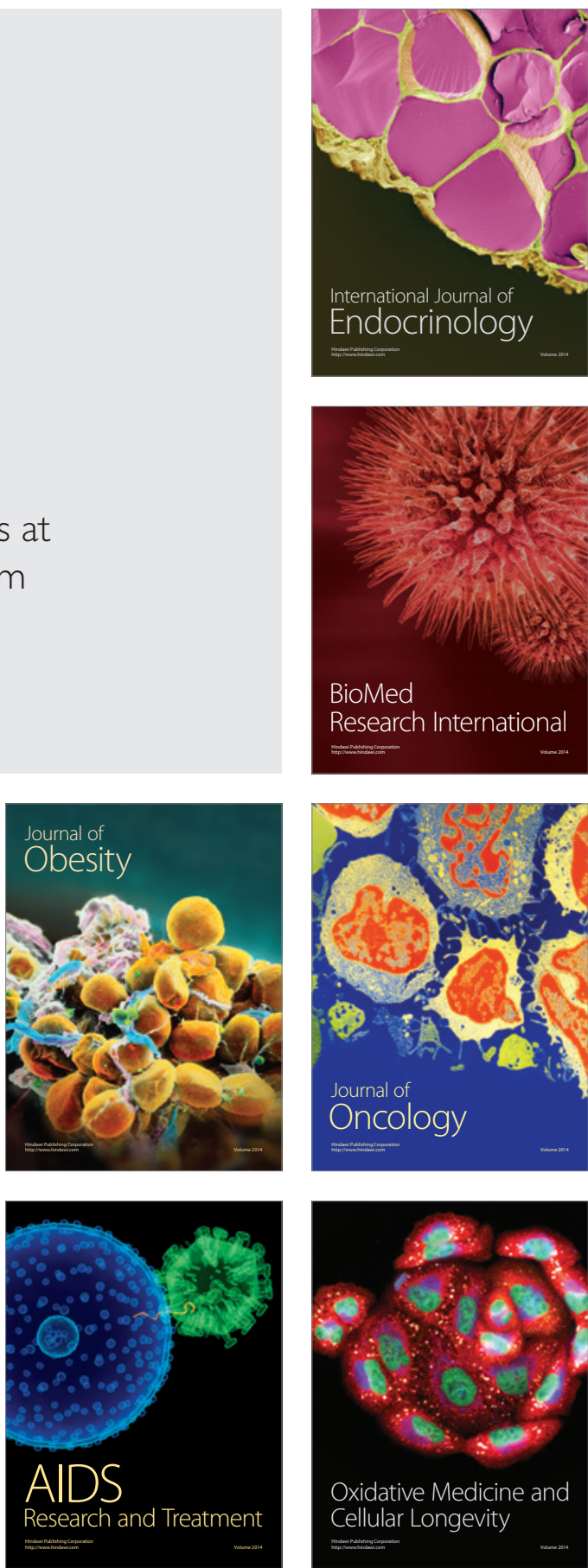